\title{
A INFLUÊnCIA DA CRENÇA RELIGIOSA NA MOTIVAÇÄO DE UMA CLIENTE PARA O AUTOCUIDADO
}

Luiza Akiko Komura Hoga*

HOGA, L.A.K. A influência da crença neligiosa na motivação de uma cliente para o autocuidado.Rev. Esc. Enf. USP, v. 27, n. 1, p. 73-85, abr. 1993.

Este é um estudo de caso sobre a influência da crença religiosa operando nas condutas de saúde de uma cliente assistida numa Unidade Básica de Saúde. A abordagem inicial da cliente foi realizada por meio da consulta de enfermagem desenvolvida no modelo teórico do autocuidado e teve sua continuidade em visita domiciliária e retorno ambulatorial. $O$ transcorrer da interação revelou que o sagrado ocupa um lugar importante nas decisóes desta cliente em relação à sua saúde.

UNITERMOS: Consulta de enfermagem. Autocuidado. Crença religiosa.

\section{INTRODUÇÃO}

Tenho realizado, nestes últimos anos, meu trabalho em uma comunidade rural, em conjunto com os membros do Núcleo de Assistência para o Autocuidado da Mulher (NAAM), na Unidade Básica de Saúde de Vargem Grande Paulista (UBS-VGP). A prática assistencial de enfermagem deste grupo é fundamentada no modelo teórico do autocuidado; nela são realizadas consultas de enfermagem e trabalhos grupais na área de saúde da mulher, com enfoque principal na prevenção do câncer ginecológico.

No exercício dessa prática tenho observado que as crenças e valores da população atendida são marcantes na sua conduta em relação à sua saúde. Muitas foram as experiências com relaçāo a influência da cultura sobre as condutas em relação à saúde, porém chamou-me a atençāo a predominância do fator religioso em muitas das mulheres atendidas.

Pretende-se nesta oportunidade, apresentar um estudo de caso sobre uma cliente em quem a crença religiosa foi crucial para a decisão de procurar um serviço de saúde.

\section{MODELO TEÓRICO DO AUTOCUIDADO}

As atividadesdesenvolvidas pelos membros do NAAM alicerçam-se no modelo assistencial de enfermagem de OREM (1990) cuja essência é a valorização do próprio cliente no desempenho de atividades para benefício próprio. Esta teorista de enfermagem é de opinião que o poder de tornar-se agente do

\footnotetext{
* Enfermeira. Assistente do Departamento de Enfermagem Matemo-Infantil e Psiquiátrica da Escola de Enfermagem da Universidade de Sāo Paulo.
} 
scu autocuidado desenvolve-se no processo do viver diário, onde acumulam-sé as experiências aprendizagem.

Nesse processo de desenvolvimento do indivíduo, OREM (1990) reconhece a existência de três tipos de autocuidado, a saber: o primeiro, que a autora denominou de cuidados universais, é representado pelas atividades diárias indispensáveis à sobrevivência do ser humano, como alimentar-se, dormir, etc; o segundo diz respeito aos eventos do ciclo evolutivo do homem, como puberdade, paternidade e maternidade, climatério, que a mesma denomina de desenvolvimento, e, por fim, o autocuidado nos desvios da saúde, relacionado às necessidades geradas pela doença e pelas deficiências em geral. Os dois últimos implicam $\mathrm{cm}$ modificaçōes na prática do cuidar-se.

No modelo teórico de OREM (1990) preconiza-se que a enfermagem deve agir a partir das necessidades individuais dos clientes, no sentido de manter a vida e promover a saúde, prevenir as doenças e lutar contra seus efeitos. O conjunto das açōes a serem desempenhadas pelos indivíduos compõem a demanda terapêutica de autocuidado, que, quando não satisfeita, determina o "déficit"de autocuidado, ocasionando, por falta de aptidāo, informação ou motivação, causada por fatores que podem ser inerentes ao próprio indivíduo ou externos a clc.

Na ocorrência de um "déficit" potencial ou real, a enfermagem fará sua intervenção por meio dos sistemas de compensação total, parcial ou apoio educativo, de acordo com o grau de dependência imposto pelas condições do clicnte; qualquer que seja o tipo de ação, seus objetivos deverão centrar-se no indivíduo, ajudando-o a sclecionar, planejar e executar ações de autocuidado.

OREM (1990) cita fatores como idade, estágio de desenvolvimento no ciclo vital, condições de vida, grau de maturidade da personalidade, experiência de vida, estado de saúde-doença, visão de mundo e motivação para tomada de decisões, entre outros, que podem interferir diretamente na qualidade da participação do cliente no seu autocuidado. A fim de que seja garantida uma boa assistência, esta autora alerta sobre a necessidade de engajamento e responsabilidade do profissional para a busca de resultados efetivos $\mathrm{em} \mathrm{prol}$ do bem estar do cliente e para a sociedade.

$\mathrm{Na}$ orientação do cliente sobre seu próprio cuidado, estes fatores devem ser considerados, e só será concretizada se a postura profissional estiver voltada para a percepção e identificação dos comportamentos de saúde da clientela $\mathrm{cm}$ seu contexto de crenças e valores, o que pressupōe conhecimento e valorizaçāo da cultura do clientc no planejamento da assistência.

\section{O PROCESSO DE ENFERMAGEM NO MODELO DO AUTOCUIDADO}

O processo de enfermagem é uma forma sistemática de organização e provisão do cuidado de enfermagem e consiste em 4 fases: a avaliação preliminar, o planejamento, a implementação e a avaliação. OREM (1990) 
descreveu este modelo com o propósito de analisar e explicar os componentes do cuidado de enfermagem, porém alerta para o fato das fascs nem sempre ocorrerem de forma linear, pois dois ou mais componentes do processo podem ocorrer simultancamente.

\section{Avaliação Preliminar}

Esta fase fornece dados baseados no poder do cliente, entendida neste modelo como as açōes de autocuidado, interesses e problemas a identificar. A base de dados nesta fase é obtida por meio de histórico de enfermagem, a entrevista e o cxame físico, que nos propiciam uma visão geral do cliente e scrão essenciais para as etapas subseqüentes.

\section{Histórico de Enfermagem}

São utilizados questionários em que os próprios clientes completam os dados, o que os envolve mais ativamente no processo. Deve ser elaborado de maneira simplificada, com questōes fechadas e vocabulário acessível, que facilite seu preenchimento.

Incluem dados relativos à identificação, estados de saúde e doenças prévias, dados sobre scu desenvolvimento, revisão de sistemas orgânicos e práticas que promoveram sua saúde c preveniram a doença. Perguntas sobre revisão de sistema, dão informações sobre condições passadas e presentes, acidentes, doenças e hospitalizaçōes, englobando grandes áreas anatômicas do corpo. Estes dados ajudam o cliente e o enfermeiro no grupamento de sintomas e práticas de saúde e as suas relaçōes.

Alguns dados sócio-culturais são importantes, como por exemplo, saber quais são as pessoas que o cliente mais considera e quem são as pessoas que ela procura quando está precisando de ajuda. No autocuidado, a noção de família, seja ela do tipo nuclear ou extensa, é considerada importante pois a mudança na saúde em algum de seus membros pode afetar o conjunto. Pergunta-se ainda sobre os fatores hereditários, que são importantes na causa e expressão de certas condiçōes.

Informaçōes como ocupação, nível educacional, exposição a poluentes, condições sanitárias, estilo de vida, história sexual, recreação, relação com o trabalho, etnicidade e religião também sāo importantes para a enfermagem. Principalmente estas últimas têm grande significação nos rituais de nascimento, morte e visões sobre saúde e doença.

\section{Entrevista}

Com os dados do histórico auto aplicado em mãos, segue-se para a entrevista. Esta não se inicia perguntando-se por quê o cliente procurou o sistema de saúde, pois isto implica em um diagnóstico médico e orientação sobre a doença. No autocuidado, prefere-se perguntar sobre a motiváăão do 
cliente para a procura do cuidado, pois assim descreve-se a razão do cliente para a visita e a percepção individual sobre a necessidade de saúde.

O enfermeiro deve incluir perguntas para se obter uma noção geral das atividades de saúde do cliente, seus hábitos mais comuns, sua nutrição, sono e repouso e outros comportamentos de autocuidado no sentido geral. Deve-se favorecer a manifestação de crenças e valores acerca da saúde e principalmente, elucidar a percepção do cliente/família no que se refere a sua suscetibilidade.

$\mathrm{Na}$ sequência, iniciam-se as intervençōes de enfermagem, dando orientações consideradas necessárias, ou solicitadas pelo cliente, de acordo com o que foi identificado, respeitando-se a bagagem cultural expressa pelo cliente. Durante as intervenções aprofunda-se a interação profissional-cliente, criando-se condiçōes para a abordagem de assuntos de foro mais íntimo, que porventura o cliente demonstre querer discutir com o enfermeiro.

$\mathrm{Na}$ fase da entrevista é fundamental o estabelecimento de empatia para o êxito do processo, que, quando logrado, traz inegável benefício ao cliente. Ressalta-se aqui, a importância de nunca se adotar uma postura autoritária, propiciando condiçócs para que o cliente sinta-se à vontade para falar.

Este método de trabalho sem dúvida traz benefícios para a qualidade da assistência, porém deve-se dispor de tempo suficiente para atingir a devida profundidade e a obtenção de dados de forma sistemática. Na fase da entrevista, deve ser dado atenção especial para alguns clientes,como analfabetos ou imigrantes que năo entendem a língua.

Além dos dados fornecidos pelo cliente, as informações podem ser recolhidas dos registros médicos, membros da família ou a migos que acompanham o cliente.

\section{Exame Físico}

Correlaciona-se neste momento todos os dados das fases anteriores, ou seja, do histórico de enfermagem auto aplicado e da entrevista. É um tempo importante para conseguir mais dados e ensinar o autocuidado, pois cada tcmpo do exame físico é uma oportunidade do enfermeiro fazer questōes específicas sobre determinada parte do corpo.

A fase de avaliação preliminar do processo de enfermagem é completada com um diagnóstico de enfermagem, que no autocuidado é a relação entre demanda terapêutica e déficit de autocuidado, e a partir delas são estabelecidas metas de autocuidado.

Ao término desta fase, o enfermeiro tem um perfil geral de seu cliente e ciência sobre os fatores de risco envolvidos e pode identificar todos os riscos potencialmente modificáveis por meio de práticas de autocuidado. 
Além disso, tem-se o esboço do poder do cliente, que inclui saber o que ele faz cm prol de sua saúde. Cabc neste momento que o cliente faça uma auto-avaliação, levando-o a relacionar os vários fatores envolvidos e aproveitar esta oportunidade para ensinar o cliente a buscar as soluçōes apropriadas, que o ajudará a aumentar seu senso de auto-controle e poder. Esta fasc encerra-se com o estabelecimento das necessidades de saúde do cliente.

\section{Planejamento}

Nesta fase estabclecem-se metas bascadas nessas necessidades e sugeremse intervençōes específicas para atingi-las, obedecendo a determinados critćrios. O primeiro é o apontamento de prioridades, dando uma ordem de importância às metas traçadas. Assim, tanto o enfermeiro quanto o cliente devem decidir se a meta é realística e pode ser atendida, pois ao contrário, poderia scr uma fonte de frustação que deve ser cvitada.

Estabelecidas as metas, deve-se determinar se a necessidade é de conhecimento, habilidade ou requer uma mudança comportamental, e verificar, ainda, se o sistema é de compensaçăo total, parcial ou de apoio educativo.

O segundo critério a ser observado é o estabelecimento de uma meta $\mathrm{cm}$ um determinado tempo, e permitir tempo suficiente, pois um sucesso ajudará na conquista do próximo desafio.

Ao final da fase de planejamento, estabelecem-se critérios de avaliação, que devem ser suficientemente claros, objetivos e mensuráveis.

\section{Implementação}

É a hora de sc colocar o plano em ação, onde todos os esforços devem ser concentrados para se alcançar êxito na empreitada. Por exemplo, deve-sc esclarecer o cliente para manter-se atento às sabotagens de todos os tipos, como por exemplo, ir frequentemente a restaurantes de massa quando se quer perder peso e propiciar alguns fatores facilitadores, como deixar lembretes para evitar csquecer-se de algo estabelecido como importante.

\section{Avaliação}

Avaliam-se as metas traçadas, refletindo sobre a forma como aconteceram as mudanças e as habilidades de auto-cuidado.

O processo de avaliação deve scr feito junto com o cliente e de forma a abranger o conjunto do processo, sobretudo os critérios pré-estabelecidos, questionando-se sua apropriação e reconhecendo-se as suas limitaçōes e barreiras.

\section{O ESTUdO de CASO COMO FORMA de INVESTIGAÇĀO}

O estudo de caso, conforme preconizam LUDKE; ANDRÉ (1986) é o estudo de um caso, seja ele simples ou complexo. Deve ter seus contornos 
claramente definidos e seu interesse deve incidir sobre o que ele tem de particular, adquirindo, assim um valor em si mesmo. Pode scr considerado qualitativo quando for desenvolvido numa situação natural, com dados decritivos que focalizem a rcalidade de forma complexa e contextualizada.

LUDKE; ANDRÉ (1986) destacam como características fundamentais do estudo de caso:

a) a preocupaçāo pela descoberta ou a constante atençāo $\mathrm{cm}$ relaçāo a novos elementos que podem emergir durante o esludo;

b) a ênfase em interpretá-la no contexto em que ela ocorre;

c) a preocupaçăo em revelar os vários fatores presentes na situação e a inter-relação dos seus comprovantes;

d) ser baseada numa variedade de fontes de informação;

e) o pesquisador relata suas próprias situaçōes;

f) exposição sobre o ponto de vista do pesquisador em caso de divergência, $\mathrm{cm}$ presença de pontos conflitantes em determinada situação social;

g) possibilidade de formas variadas de relatos, em geral, de mancira informal e na rrativa, preocupada com a transmissão direta, cla ra e articulada do caso.

Scgundo estas autoras, existem várias manciras de se proceder um estudo de caso, mas basicamente é composta de uma fase exploratória, uma de coleta de dados c a terceira que consiste na análise, interpretação e sua apresentação. Tais fases não ocorrem de maneira linear, sendo portanto, difícil delimitar um ponto que as separem.

\section{DADOS DE INTERESSE PARA ESTE ESTUDO DE CASO}

Neste estudo, os dados foram coletados no decorrer da aplicação de um processo de enfermagem, realizada no modelo do autocuidado.

A cliente, alvo deste estudo, é uma mulher que veio espontaneamente à UBS-VGP para fazer exame preventivo para câncer ginecológico. Como trata-se de uma cliente escolhida para estudo de caso, realizou-se ta mbém uma visita domiciliária (VD) com a finalidade de aprofundar o estudo c captar dados de seu contexto familiar, e sua vida cotidiana.

Além disso, foi possível analisar dados contidos no prontuário da cliente e outras informaçóes coletadas durante seu retorno ambulatorial. Tais dados foram sumarizados para apresentação neste estudo.

\section{Dados de Identificação, Familiares e Sociais}

Tem ela 40 anos, de cor branca, escolaridade $2^{a}$ série do $1^{\circ}$ grau, religião "crente". É casada e reside com o marido e 4 filhos, em casa própria, de alvenaria, contendo 3 cômodos, com água encanada, esgoto, luz clétrica e situa-se em um bairro periférico a cerca de $2 \mathrm{Km}$ da cidade. Ocupa-se de serviços domésticos; scu marido trabalha como marcenciro autônomo, em sociedade com outra pessoa c seus filhos são estudantes.

Estcs dados, associados com os da entrevista e do exame físico, permitiram estabelccer a demanda tcrapêutica $\mathrm{c}$ os déficits de autocuidado. 


\section{DEMANDA TERAPÊUTICA E DÉFICIT DE AUTOCUIDADO}

Tem ciência de que é portadora de diabetes, porém não faz nada neste sentido. Gostaria mas não sabe fazer ginástica e está sofrendo um processo de auto-imagem corporal negativa. Os valores da pressão arterial estão alterados, e não faz acompanhamento ambulatorial.

Desconhecimento do auto-exame de mama, sendo pertencente ao grupo de risco para câncer de mama. Periodicidade inadequada de higiene oral.

Estes dados foram trabalhados conforme a Estrutura Conceitual de Enfermagem OREM (1990), que pode ser vista a seguir.

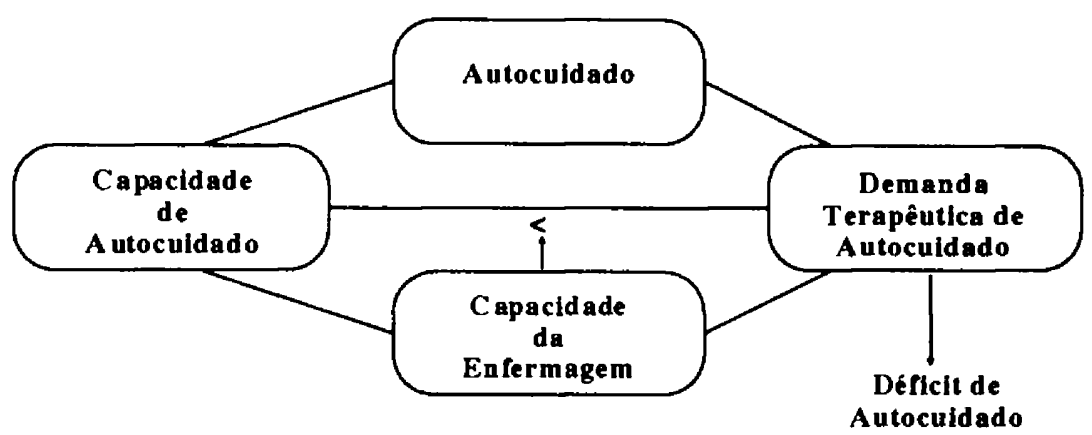

De acordo com esta teoria, o enfermeiro deve atuar favorecendo um equilíbrio entre a capacidade de autocuidado e a demanda terapêutica de autocuidado, que quando nāo esiver sendo satisfeita, determina o déficit de autocuidado.

Assim sendo, a demanda terapêutica e o déficit de autocuidado levantados foram estes explicados para a cliente, de maneira clara, pois, segundo OREM (1990), os objetivos da assistência deverão estar centrados no indivíduo, que deve ser orientado em como selecionar, planejar e executar açōes de autocuidado. A fase de avaliação ao cliente encerra-se com o estabelecimento das necessidades de saúde do cliente e passa-se para a etapa de planejamento do cuidado e sua implementação. Segundo o critério estabelecido pelo modelo do autocuidado, estabeleceram-se as metas, que foram traçadas visando o atendimento da demanda terapêutica e déficit de autocuidado.

Vcrificou-se que as necessidades da cliente abrangiam itens referentes às três áreas, ou seja, de conhecimento, de habilidade e de atitude. Quanto ao tipo de intervenção, listadas a seguir, podem ser classificadas, em sua maioria como sendo apoio educativo.

Orientação sobre alguns tipos de exercícios físicos. Esclarecimento sobre os tipos de alimentos que contêm mais calorias. Orientação sobre fatores que 
levam à disfunção do padrão alimentar como, por excmplo, associação da alimentação a outras atividades, concentração da ingestāo para algum período do dia, alimentação em resposta a uma situação interna que não é fome. Encaminhamento à clínica médica. Orientação sobre as fontes de estresse, $\mathrm{e}$ sugestōes para a cliente reduzí-las, e ensino de técnicas de relaxamento. Orientação sobre redução do sal na dieta. Ensino da técnica do auto-exame de mama e dos demais itens relativos a esta prática (época, periodicidade). Orientação sobre a importância da periodicidade da higiene oral.

\section{AVALIAÇÃO F EVOLUÇÃO DA ASSISTÊNCIA DE ENFERMAGEM}

Esta fase seria completada, conforme a rotina, no retorno de enfermagem agendado, oportunidade em que é fornecido o resultado do exame de Papanicolau e é realizada uma intervenção com o grupo de mulheres, visando educação para a saúde. Para esta cliente, como se trata de um estudo de caso sobre crença religiosa influindo sobre a prática do autocuidado, fez-se um VD para observar o contex to de seu cotidiano e tentar captar e compreender como suas crenças influem no seu estilo de vida.

$O$ conjunto interrelacionado de fatores que influem as pessoas em suas ações relativas à saúde é explicada por BOWER (1985), no seu Modelo de Crenças em Saúde. Este autor julga que as decisões sobre os comportamentos preventivos de saúde, buscadas por uma pessoa, dependem do valor atribuído ao scu resultado e das chances que se têm de alcançá-los.

Cabe ressaltar que esta cliente foi esclarecida de que receberia uma V.D. após determinado período, para avaliação das metas traçadas e para alguma intervenção de enfermagem adicional.

Esclarece-se que todos os procedimentos realizados durante a VD transcorreram de maneira informal, realizando-se uma avaliação conjunta das metas traçadas e aprofundando-se, durante a entrevista, na questão da religiosidade, além da preocupação da pesquisadora em observar aspectos de sua vida diária.

Durante os momentos da interação com a cliente, pôde-se captar que sua religiosidade exerce grande influência sobre suas ações relativas à saúde, cujo Reverendo parece representar o papel de guia de suas ações.

Tais influências podem ser percebidas em vários aspectos:

No âmbito da procura pelo serviço de saúde, seu ponto de partida para esta decisão foi que "se Deus fez vocês (profissionais de saúde) é para ajudar a Sua obra". Depois que entrou para a igreja foram-lhe "reveladas" muitas doenças como úlcera no estômago, inflamação no útero, leucemia e quando "Deus revela", devemos crer na sua revelação (aviso), e "quando cremos , Deus cura".

Mas, segundo esta cliente, "existem muitas enfermidades que não são do corpo, e sim đo espírito". "Leucemia, inflamação no útero e úlcera são doenças 
da carne e o médico consegue achar". "Quando não é da carne (macumba) o médico nāo acha, pois só Jesus tem poder sobre a carne e a enfermidade maligna (do espírito)". Neste caso, deduz-se que a procura pelo médico foi a "doença do corpo" que o "médico pode achar", já que "o médico também é obra de Deus", cntão ele deve ser procurado para pedir ajuda.

Quanto à hipertensão e diabetes, a cliente referiu que "tem orado para Deus pela sua misericórdia", pois a pressão arterial aumentada "não foi revelação de Deus", mas precisa de tratamento médico. Na época da V.D., esta cliente ainda não tinha agendado uma consulta médica, conforme havíamos estabelecido nas metas, e este fato foi justificado pela cliente, que estava esperando uma "revelação divina sobre a doença", para, então, crer nela, pois, segundo ela "quando cremos na revelação, Deus cura". Esta cliente revelou que apesar desta crença, pretende ir ao médico para tratar da hipertensão, quando criar coragem, pois também acredita na cura que o médico pode dar.

A VD permitiu verificar outros dados sobre as açōes programadas. Quanto à alimentação, pôde-se observar a não aceitação do tipo de alimento recomendado, a alimentação fugia totalmente do planejado na assistência. Questionada sobre as condições monetárias para aquisição de alimentos adequados e sua conservação, ela respondeu que pode adquiri-los, porém, a adoção do sistema planejado implicaria numa alteração do hábito alimentar de sua família. Além disso, justificou como não aderente porque "não estava sentindo nada". Verficada a pressão arterial na VD, esta se encontrava em $140 \times 90 \mathrm{mmHg}$, o que de certa forma justifica a ausência de sintomatologia hipertensiva.

Sobre o "nervosismo" referido na consulta, houve a manifestação da própria cliente atribuindo a causas do mesmo às suas próprias condiçōes de sobrevivência c a presença de 2 filhos "bagunceiros que não me davam sossego". Segundo a cliente, "o nervoso Deus já me revelou e foi porque ela pegou uma macumba e Deus ainda não teve misericórdia porque ainda não chegou a hora" c cla acha que pode ser devido ao café que toma em demasia.

Quando questionada sobre um aborto provocado, ela csclareceu que isto aconteceu antes de entrar para esta religiāo, pois antes já pertenceu à Igreja Católica e também fez parte de um Centro de Umbanda. Atualmente convive bem com o seu passado "triste", pois "já pediu a misericórdia de Dcus para perdoar seus pecados". Obteve a mesma "misericórdia" com o hábito do fumo e do álcool, pois a tualmente nāo possui estes vícios.

Sobre a laqueadura tubária, que é condenada pela sua igreja, a cliente revelou que o fato de ter sido feita na mesma ocasião da cesárea, que tinha indicação médica, no caso a perineoplastia anterior, não traz problemas de conflito e portanto "não tem arrependimento da cirurgia". "Se tivesse sido parto normal não poderia ter feito a laqueadura". Antes de entrar para csta igreja, tomava pílula anticoncepcional, mas depois não pôde mais tomar, então engravidou mais duas vezes. 
No que se refere ao auto-exame de mama, não a tem realizado, embora tenha demonstrado lembrar bem dos passos e justifica a sua não aderência à prática preventiva pelo fato de crer que quando existe o problema, a pessoa percebe pois "dói e começa a crescer".

No conjunto das ações de enfermagem propostas, pode-se observar que a higiene oral e os exercícios físico foram os únicos que foram regularmente seguidos por esta cliente. A justificativa para os cuidados universais foi que "Dcus manda tomar banho todo dia e escovar os dentes" além de estar realmente sentindo necessidade de escovar os dentes diariamente. Quanto aos exercícios físicos, principalmente para a redução do abdômen, cla os tem realizado e já se refere notar alguma diferença. Cabe lembrar que o desejo de aprender alguns exercícios partiu da própria cliente, no momento da consulta de enfermagem.

A pouca aderência desta cliente às metas traçadas corroboram com os estimados por BOWER (1985), segundo o qual o índice de năo aderência varia de 20 a $60 \%$ conforme a situação. Este autor afirma que o seguimento ou abandono de meta em termos de saúde está intimamente associada ao processo de educação do paciente $\mathrm{e}$ não pode estar rigidamente ligada às metas do tratamento. Enumera, ainda, três clementos que compóem a aderência ao tratamento: o conhecimento, a atitude e o comportamento. Considerando-se a abrangência que estes elementos alcançam, a aderência caracteriza-se pela complexidade, pela demanda na mudança de comportamento do indivíduo e pela sua instabilidade sendo, portanto, muito difícil mensurá-la.

Diante destes problemas ou fatores que interferem no processo de educação do paciente, resta para o profissional de saúde, a negociação cultural do cuidado, conforme preconiza OREM (1990). Para tanto, torna-se fundamental o cstudo mais profundo dos valores c de suas crenças no contexto social em que o cliente está inscrido, năo se limitando apenas ao sentido restrito da saúde, pois, para BOWER (1985), a saúde é um dos componentes do seu sistema de valores e nem sempre são os mais valorizados na hicrarquia.

Valor de sc conhecer melhor a cultura do cliente quando se pretende prestar assistência na abordagem da saúde se clareiam nestc cstudo onde, no conjunto de atos que compõem seu cotidiano evidenciou-se o sagrado ocupando lugar importante na sua hierarquia de crenças e valores. Nos dizeres de MACEDO (1986), ao tratarmos da questão do sagrado, não nos cabe indagar sobre a oposiçāo falso/verdadeiro; afirma que "se o sagrado dá lugar a ações específicas, a representaçõcs explícitas, scu modo de operação não apenas pode como deve ser avaliado pela capacidade que tem de estruturar os espaçostempos cotidianos". No seu entender, o sagrado vincula-se aos projetos de vida c ocupa lugar crucial na ordenação das signifcações que vão produzir estes projetos. 
No presente estudo, o aprofundamento sobre as influências exercidas pela crenças no poder divino determinou o rumo da assistência na direção de situá-la historicamente quanto à sua religiosidade e negociar a assistência, preocupando-se em preservar sua bagagem cultural e lembrando-a de que o profissional de saúde sempre se dispõe a prestar sua contribuição.

Aos profissionais da área de saúde, dentre eles a(o) enfermeira(o) cabe refletir sobre estas questōes e aprofundar seu conhecimento na área.

MONTERO (1985) realizou um estudo antropológico sobre pessoas que procuram a cura no terreiro de umbanda $e$ analisando um conjunto de falas sobre "doença maternal" e "doença espiritual" chegou a uma conclusāo pouco esclarecedora: que "uma doença é espiritual porque não é material". Entretanto, esta pequena conclusão ganha sentido e nos leva a uma autocrítica da própria profissão, e no sentido amplo, da assistência à saúde prestada, pois, segundo esta pesquisadora, a cura mágica não é vista como complemento ao tratamento médico, mas como algo que se contrapõe, seja porque a medicina fracassa ao tentar resolver os problemas do paciente ou porque desconsidera suas queixas como pertinentes à descrição de alguma entidade mórbida.

Um outro aspecto merece atenção e deve ser considerado por parte dos profissionais prestadores de assistência à saúde. Trata-se da questão da imagem que o usuário tem sobre a forma pela qual são vistos pelo sistema de saúde, visão esta, geralmente restrita aos limites dos acontecimentos puramente fisiológicos, descartando as outras dimensões presentes. MONTERO (1985), na população de seu estudo encontrou esta concepção sobre a assistência de saúde, e supõe que a procura dos doentes pela solução mágica deve-se ao fato de discurso religioso possibilitar ao indivíduo expressar e viver sua pessoa de forma holística, pois nesta visão integral do ser humano, segundo esta autora, a ação profilática "deixa de ser uma simples intervenção técnica sobre o corpo a fim de eliminar sintomas e suas causas orgânicas", e passa a ter uma visão mais globalizante, de capacitação para compreender-se como ser no m undo, atuante e capaz de dar sentido às tensões a que vive submetido.

Na visão de MACEDO (1986), a religião vincula as questōes práticas da cxperiência humana com uma ordem cósmica imaginada, e esta projeta-se nas ações, de tal modo, que a vivência cotidiana é atravessada por um esforço de incorporar a experiência pessoal no cerne de uma visão mais ampla e significativa da sociedade em que se vive e do próprio sentido da existência, onde a representação da realidade é permeada por uma concepção de Deus. Estas consideraçóes implicam, segundo a autora, em reconhecer a autoridade da ação religiosa persuadindo a determinação de um conjunto de símbolos e orientando a ação.

A dificuldade de mensurar a aderência às propostas faz-se presente, também neste caso, pois se pode afirmar que o maior grau de não aderência tenha sido, devido ao predomínio de sua crença na proteção divina, à credi- 
bilidade ainda insuficiente nos serviços profissionais ou às próprias dificuldades impostas pelo seu cotidiano, assim como a própria distância para chegar à instituição de saúde, ou a mescla de todos estes fatores.

Estas impressões, captadas no decorrer da assistência, reforçam as consideraçōes de ROSENSTOCK (1974) de que a aceitação da suscetibilidade à doença, e portanto a crença na sua gravidade, reúnem forças para a tomada de decisões, mas nem sempre levam ao curso esperado de ações.

\section{CONSIDERAÇÕES FINAIS}

Para a realização deste "estudo de caso" $\mathrm{cm}$ que se procurou estudar a influência da crença religiosa incidindo sobre as açōes de saúde desta cliente, foi fundamental o estabelecimento de uma relação empática que foi favorecida pela abordagem centrada nas necessidades da cliente, conforme preconiza 0 modelo assistencial do autocuidado.

Para se aprofundar o estudo, a VD se mostrou muito útil na captaçāo de experiências concretas de sua vivência e no encontro de uma explicação de como as pessoas funcionam em scus meios particulares. Seria mais enriquecida se houvesse a possibilidade de um contato mais prolongado, inclusive com outros membros de sua comunidade religiosa.

Neste sentido, ROAZZI (1987) sugere o aproveitamento de situaçōes naturais (contexto ambiental do sujeito pesquisador), associado ao contexto de laboratório (instituição de saúde), principalmente quando se visa o estudo de aspectos culturais e problemas da vida real cotidiana, para não se correr o risco de se chegar a conclusões simplistas.

No transcorrer das interaçōes observou-sc a satisfação da cliente em ser alvo de um estudo, visto a disponibilidade $\mathrm{e} o$ interesse demonstrado em todas as fases do mesmo. Embora a aderência ao plano de autocuidado não tenha sido integral, pelos motivos já discutidos, este estudo teve seu valor pela satisfação da cliente com a assistência recebida o que constitui, segundo CHANG (1980), uma legítima medida de qualidade do cuidado.

Finalizando, OREM (1980) sugere três níveis de prática para o enfermciro: o social, o interpessoal e o tccnológico. Aplicando estes níveis na prática assistencial, com enfoque no autocuidado, pode-se dizer que ele favorece um contato mais cfetivo e aletivo com a clientela (nível social), propicia condições para dar ajuda profissional (nível interpessoal) e cria a possibilidade de intervenção por meio de atividades específicas de enfermagem (nível tecnológico).

Contudo, deve-se estar atento para que não estabeleça grau de dependência difícil de ser solucionado, pois esta filosofia de assistência busca o outro lado do fio, ou seja, a independência do cliente. 
Estc estudo, por ter sido restrito a uma cliente, ć limitado e nos impulsiona a estudar o assunto de mancira mais profunda e abrangente, com clientes de diversas comunidades religiosas, o que seria possível e mais enriquecido pelo desenvolvimento de pesquisas que enfoquem a diversidade $\mathrm{e}$ a universalidade cultural do cuidado.

HOGA, L.A.K. Influcnce of religious beliefs on the motivation for selfcarc. Rey_Esc.Enf. USP, v. 27, 11. 1, p. 73-85, a pr. 1993.

This is a case study on the influence of religious beliefs interferinfg in the clients health actions in an outpatient unit. The initial approach of the client w'as made by a nursing consultations using selfcare framework. The continuity of intervetion w'as perfomed by home visit and follow'-up consultation. The development of the interaction revealed that the holy occupies important place in the clients'decision in relation to her health.

UNITERMS: Nursing Consultation. Selfcare. Religious Belief.

\section{REFERÊNCIAS BIBLIOGRÁFICAS}

BOWFR, K.A. Complience as a patient education issue. In: WOL.DUM et al. Patient education. Rockville, An Aspen Publication, 1985. cap. 3, p. 45-114.

CHANG, B.L. Facilitating self-care: review of the literature and a onnceptual model. $\Delta$ NS, v. 3, n. 1, p. $43-58,1980$.

LUDKE, M.; ANDRÉ, M.E.D.A. Pesquisa em educaçăo: abordagens qualitalivas, Sāo Paulo, Pedagógica e Universitária, 1986.

MACFiDO, C.C. Tempo de gênesis. Sāo Paulo, Brasiliense, 1986.

MONIT:RO, P. Da doençà à desondem: a máfia na umbanda. Rio de Janeiro, Graal, 1985. cap. 3, p. 117-76: ^ percepçăo popular da docnça e sua reinterpretaçăo religiosa.

OREM, D.E. Nursing: concepts of pratioe. New York, MacGraw-llill, 1990.

ROAZZI, A. Pesquisa e contexto: métodos de investi gaçāo e diferenças sócio-cul turais em questăo. Cad. Pess., n. 62, p. 35-44, 1987.

ROSENSTOCK, I.M. Ilistorical origins of the Health Belief Model. Health ED. Mon., v.2, n. 4, p. 328-35, 1974. 